\title{
Perceived stress and its associated factors among pregnant women in Bale zone Hospitals, Southeast Ethiopia: a cross-sectional study
}

\author{
Nigus Alemnew Engidaw ${ }^{1 *}$, Alemayehu Gonie Mekonnen ${ }^{1}$ and Fetene Kassahun Amogne ${ }^{2}$
}

\begin{abstract}
Objectives: Even though perceived stresses during pregnancy adversely affect the mother and her baby, there is still a scarcity of data from developing countries including Ethiopia. Therefore, this study assessed the prevalence of perceived stress and associated factors among pregnant women in Bale zone hospitals, Southeast Ethiopia. Crosssectional study was conducted from November 2016 to April 2017. A total of 396 pregnant women were successfully interviewed using structured and pre-tested questionnaires. Perceived stress scale was employed to assess the women's stress status. A systematic random sampling technique was used. Logistic regression was applied to identify factors associated with perceived stress and statistical significance was considered at $p$-value $<0.05$.

Results: In this study, the prevalence of perceived stress among pregnant women was $11.6 \%(95 \% \mathrm{Cl} 8.30,14.60)$. Having 2-5 pregnancies previously ( $A O R=9.82 ; \mathrm{Cl} 1.08,89.5)$ and gestational age less than 12 weeks $(\mathrm{AOR}=3.53 ; \mathrm{Cl}$ $1.03,12.08$ ) were associated with perceived stress among pregnant women. In this study, the prevalence of perceived stress among pregnant women was relatively low. Health care providers should give due attention to the screening of stress in the first trimester to reduce the likelihood of pregnancy-specific stress.
\end{abstract}

Keywords: Perceived stress, Pregnancy, Bale zone hospitals

\section{Introduction}

Stress is a complex pattern of a reaction of the human physiology to a demanding situation. It is a process in which we perceive and deal with threats and challenges around us [1]. Even though pregnancy is often considered as an exciting time, it has a stressful journey in a productive woman's life that needs a significant emotional adjustment $[2,3]$. Stress during pregnancy is defined as the imbalance that a pregnant woman feels when she cannot deal with demands and worries [4]. Worldwide, stress is a very common mental health problem among women during their time of pregnancy [5]. Studies reported that the prevalence of stress during pregnancy range from 5.5 to $78 \%[5-12]$.

\footnotetext{
*Correspondence: nigusalemnew2014@gmail.com

1 Department of Nursing, College of Health Sciences, Debre Berhan University, Po. Box 445, Debre Berhan, Ethiopia

Full list of author information is available at the end of the article
}

A number of biopsychosocial risk factors contribute to perceived stress during pregnancy. Important factors among them were a past history of depression, domestic violence, stressful life events and interpersonal conflicts $[13,14]$. Women who experience high levels of stress are more likely to be from low socioeconomic status [14], less than 20 years of age, being single, have less than grade 11 educations and have no good social support [15]. In a study done Macao, China also showed that women who were separated, divorced or cohabiting were more likely to appraise their lives as stressful [16]. Other researchers have also established that partners conflict during pregnancy leads to pregnancy-related concerns $[17,18]$ and emotional pain [19]. For example, Poor marital adjustment is known to predict a higher degree of bothers during pregnancy [18]. A Systematic Review among pregnant women illustrates that increased maternal stress was associated with gravidity, gestational age at delivery and monthly family income [1].

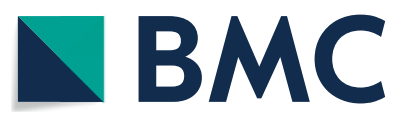

(c) The Author(s) 2019. This article is distributed under the terms of the Creative Commons Attribution 4.0 International License (http://creativecommons.org/licenses/by/4.0/), which permits unrestricted use, distribution, and reproduction in any medium, provided you give appropriate credit to the original author(s) and the source, provide a link to the Creative Commons license, and indicate if changes were made. The Creative Commons Public Domain Dedication waiver (http://creativecommons.org/ publicdomain/zero/1.0/) applies to the data made available in this article, unless otherwise stated. 
Mild level of perceived stress during pregnancy is good for the most favorable development of the fetus, but if it goes beyond it may lead to long term effect on the fetus, and change the development of the fetal nervous system [20]. Stress at the time of pregnancy is also associated with preterm birth and low-birth-weight infants, the risk of gestational hypertension, and undesirable health and behavioral outcomes which lead to infant mortality, cerebral palsy, delays in development, vision and hearing impairments $[21,22]$. It has also an effect on the formation of a safe attachment bond with the newborn [23, 24]. Demanding life events before the time of delivery is also linked with the mental health problems in childhood, adolescent and adulthood [25].

Even though perceived stress during pregnancy adversely affects the mother and her baby, there is still a scarcity of data from developing countries including Ethiopia. Therefore, this study assessed the prevalence of perceived stress and associated factors among pregnant women in Bale zone hospitals, Southeast Ethiopia.

\section{Main text}

\section{Study area and period}

The study was conducted from November 2016 to April 2017 in Bale zone hospitals. These hospitals are located in the southeast part of Ethiopia. Robe, the zone city, is located $435 \mathrm{~km}$ far from the capital city of Ethiopia; Addis Ababa. The hospitals gave all types of obstetric care including antenatal care and family planning services (unpublished Bale zone health office report 2016).

\section{Study design}

A cross-sectional study design was carried out.

\section{Study population}

All pregnant women who attended antenatal care (ANC) service were the source population. Pregnant women who had known sever psychiatric illnesses which might affect the stress status of women were excluded.

\section{Operational definitions \\ Perceived stress}

It was measured with the perceived stress scale (PSS). PSS is a 7-item multiple-choice self-report psychological instrument for measuring the perception of stress. Each answer is scored 0 to 3 . PSS is scored by summing across all scale items. The total score ranges $0.0-21.0$ $[$ mean $=13.7( \pm 6.6)]$ with higher scores indicating women with more perceived stress symptoms. The cutoff value for the stress limit was set at $15[26,27]$.

\section{Sample size and sampling procedure}

The sample size was determined using a single population proportion formula: a proportion of stress among pregnant women as $37.4 \%(\mathrm{p}=0.374)$ taken from a study conducted in Ghana [12], 95\% confidence interval (CI) to be 1.96 , and margin of error to be $5 \%$. Adding a nonresponse rate of $10 \%$, the total sample size was 396 .

The total sample size was proportionally allocated to each hospital. Pregnant women were selected from the ANC unit systematically. The sampling interval was determined by dividing the number of average monthly ANC services by its sample size. The first woman was selected by lottery method from their order of discharge registration, and every third study participant at the exit of the ANC unit was included in the study.

\section{Data collection}

The structured and pre-tested questionnaire was employed. The questionnaire was prepared first in English from published articles and then translated into Amharic and Afan Oromo (local languages). Data collectors and supervisors were trained for 1 day before the actual data collection. The perceived stress level was measured with the perceived stress scale (PSS). PSS is a 7-item multiple-choice self-report psychological instrument for measuring the perception of stress [26]. Previously it has been used in studies conducted in Ethiopia [27-29].

\section{Data processing and analysis}

Data completeness and inconsistencies were checked. Epi-data version 3.1 was used for data entry and data were exported into SPSS version 22. Logistic regression analyses were applied to identify the association between perceived stress and independent variables. Independent variables that had a significant association in the bivariate analysis were entered into the multivariable analysis. A significant association was declared at a $\mathrm{p}<0.05$. The results were presented in text and tables with adjusted odds ratio (AOR) and the corresponding 95\% confidence interval.

\section{Results}

\section{Maternal socio-demographic characteristics}

A total of 396 pregnant women were successfully interviewed and the response rate was $93.6 \%$. More than half $(52.5 \%)$ of women were in the age group of less than 24 years. The mean age of the respondents was 25 $( \pm 5.44)$ years. Fifty-seven percent $(57 \%)$ of the women were Muslim and $37.3 \%$ were Orthodox Christians. The largest proportions, $(94.7 \%)$ of the women were married. Concerning the educational level of the respondents, 
$39.4 \%$ of women had completed primary education, whereas $21.2 \%$ of women had not attended formal education. Seventy-three percent of pregnant women were living in urban areas. The majority $(91.2 \%)$ of the pregnant women were living with their husband (Table 1).

\section{Obstetrics characteristics of respondents}

In this study, the mean gestational age of participants was 21 ( \pm 8.79 ) weeks and $45 \%$ of women had more than six deliveries (they were multigravida). For $85.6 \%$ of participants, their current pregnancy was planned. Around eight percent $(7.8 \%)$ of the participants reported that they had born low birth weight infant $(<2500$ g). Four percent of women reported that a history of molar pregnancy. Approximately two-third (57.8\%) of study participants used contraceptives before the current birth (Table 2).

\section{Prevalence and factors associated with perceived stress}

Overall, the prevalence of perceived stress among pregnant women was $11.6 \%$ (95\% CI 8.3, 14.6). In the bivariate analyses, marital status, the age of the respondents, the occupation of the woman, living arrangements, the status

Table 1 Socio-demographic characteristics of pregnant women in Bale zone, Ethiopia, April 2017 ( $n=396)$

\begin{tabular}{|c|c|c|c|}
\hline Variable & Characteristics & Frequency & Percent \\
\hline \multirow[t]{3}{*}{ Age } & $\leq 24$ & 208 & 52.5 \\
\hline & $25-34$ & 161 & 40.7 \\
\hline & $\geq 35$ & 27 & 6.8 \\
\hline \multirow[t]{4}{*}{ Religion } & Muslim & 227 & 57.3 \\
\hline & Orthodox & 148 & 37.4 \\
\hline & Protestant & 17 & 4.3 \\
\hline & Others $^{\mathrm{a}}$ & 4 & 1.0 \\
\hline \multirow[t]{2}{*}{ Marital status } & Married & 375 & 94.7 \\
\hline & single & 21 & 5.3 \\
\hline \multirow[t]{4}{*}{ Educational status } & No formal education & 84 & 21.2 \\
\hline & Primary education & 156 & 39.4 \\
\hline & Secondary education & 87 & 22.0 \\
\hline & College and above & 69 & 17.4 \\
\hline \multirow[t]{6}{*}{ Occupation } & Housewife & 234 & 59.1 \\
\hline & Merchant & 49 & 12.4 \\
\hline & Private employee & 31 & 7.8 \\
\hline & Farmer & 14 & 3.5 \\
\hline & Government employee & 52 & 13.1 \\
\hline & Others $^{b}$ & 16 & 4.1 \\
\hline \multirow[t]{2}{*}{ Residence } & Urban & 289 & 73.0 \\
\hline & Rural & 107 & 27.0 \\
\hline \multirow[t]{2}{*}{ Living arrangement } & With husband & 361 & 91.2 \\
\hline & Alone & 35 & 8.8 \\
\hline
\end{tabular}

\footnotetext{
${ }^{a}$ Catholic and Waqeefataa
}

b Student of pregnancy, number of pregnancy, gestational age and history of neonatal death during the previous pregnancy were associated with perceived stress. In the multivariable analysis, having 2-5 pregnancies previously and gestational age less than 12 weeks were associated with perceived stress during pregnancy. It was observed that pregnant women who had $2-5$ pregnancies were nine times more likely to develop perceived stress than those who had more than 6 pregnancies $(\mathrm{AOR}=9.82$; $\mathrm{CI} 1.08$, 89.5). In addition, the odds of developing perceived stress was higher among pregnant women who are in early gestational weeks (AOR $=3.53$; CI 1.03, 12.08) (Table 3).

\section{Discussion}

In this study, the overall prevalence of perceived stress among pregnant women was found to be $11.6 \%$ (95\% CI 8.3, 14.6). This figure is lower than the study conducted in Ireland (75.6\%) [30], Saudi Arabia (33.4\%) [7], India (33.3\%) [1], Nepal (34.2\%) [11] and Ghana (28.6\%) [12]. On the other hand, it is higher than the study done in the USA (6\%) [5] and Iran (5.5\%) [3]. This variation could be due to inadequate sample size, the difference in the geographical area and cultural practices. For example in Ireland, only 74 pregnant women were enrolled in the study [30]. The other possible reason might be, in our study, most of the pregnant women have planned pregnancy and the majority of them were living with their husband. Social support could reduce stress, hiding the effects of stress and protect pregnant women from the harmful effects of stressful situations [8]. Most of the Ethiopian society is more supportive of pregnant women. Accordingly, pregnant women have been excused from social obligations at the time of their pregnancy. Similarly, in most of the Ethiopian women and majority of the society as well, being pregnant has been considered as a blessing especially in the rural, semi-urban and religious communities. This could reduce their level of stress during pregnancy.

In this study, there is no significant association seen between socio-economic status and stress level among pregnant women. This is supported by previous studies [14, 31, 32]. Pregnant women who had 2-5 pregnancies were nine times more likely to develop perceived stress than those who had more than 6 pregnancies. This result is consistent with the previous study [6,9]. Women who had given birth before could have high levels of pregnancy-related perceived stress especially if their previous pregnancy and delivery experiences were undesirable [33]. In addition, the odds of developing perceived stress is higher among pregnant women who are in early gestational weeks. This contradicts the study in Ghana where perceived stress was higher among pregnant women who are in the third trimester [12]. The possible explanation 
Table 2 Obstetrics characteristics of pregnant women in Bale zone, Ethiopia, April 2017

\begin{tabular}{|c|c|c|c|}
\hline Variable & Characteristics & Frequency & Percent \\
\hline \multirow[t]{3}{*}{ Gravid } & 1 & 139 & 35.1 \\
\hline & $2-5$ & 212 & 53.5 \\
\hline & $\geq 6$ & 45 & 45 \\
\hline \multirow[t]{2}{*}{ Status of pregnancy } & Wanted/planned & 339 & 85.6 \\
\hline & Unwanted/unplanned & 57 & 14.4 \\
\hline \multirow[t]{3}{*}{ Gestational age } & $\leq 12$ & 86 & 21.7 \\
\hline & $13-24$ & 161 & 40.7 \\
\hline & $\geq 25$ & 25 & 37.6 \\
\hline \multirow[t]{2}{*}{ Contraceptive use before this pregnancy } & Yes & 229 & 57.8 \\
\hline & No & 167 & 42.2 \\
\hline \multirow[t]{2}{*}{ The age of her last baby (in months) $(n=226)$} & $\leq 24$ & 109 & 48.2 \\
\hline & $\geq 25$ & 117 & 51.8 \\
\hline \multirow[t]{2}{*}{ Pre-pregnancy motion sickness } & Yes & 116 & 29.3 \\
\hline & No & 280 & 70.7 \\
\hline \multirow[t]{3}{*}{ History of molar pregnancy (253) } & Yes & 11 & 4.3 \\
\hline & No & 205 & 81.0 \\
\hline & Do not know/not sure & 37 & 14.6 \\
\hline \multirow[t]{3}{*}{ Previous pregnancy with low birth weight (258) } & Yes & 20 & 7.8 \\
\hline & No & 144 & 55.8 \\
\hline & Do not know/not sure & 94 & 36.4 \\
\hline
\end{tabular}

Table 3 Risk factors associated with stress among pregnant women in Bale zone, April 2017

\begin{tabular}{|c|c|c|c|c|c|}
\hline \multirow[t]{2}{*}{ Variable } & \multirow[t]{2}{*}{ Categories } & \multicolumn{2}{|c|}{ Perceived stress } & \multirow{2}{*}{$\begin{array}{l}\text { COR } 95 \% \mathrm{Cl} \\
\text { COR }\end{array}$} & \multirow{2}{*}{$\begin{array}{l}\text { AOR } 95 \% \mathrm{Cl} \\
\text { AOR }\end{array}$} \\
\hline & & Yes & No & & \\
\hline \multirow[t]{2}{*}{ Marital status } & Married & 41 & 334 & 1 & 1 \\
\hline & Single & 5 & 16 & $2.55(0.13,1.12)$ & $1.75(0.15,20.07)$ \\
\hline \multirow[t]{3}{*}{ Age of the respondents } & $\leq 24$ & 24 & 184 & $3.39(0.44,26.14)$ & $2.28(0.82,6.37)$ \\
\hline & $25-34$ & 21 & 140 & $3.90(0.50,30.27)$ & $1.44(0.10,20.28)$ \\
\hline & $\geq 34$ & 1 & 26 & 1 & 1 \\
\hline \multirow[t]{5}{*}{ Occupation } & Housewife & 23 & 212 & 1 & 1 \\
\hline & Merchant & 5 & 44 & $1.07(0.386,2.98)$ & $0.71(0.044,11.58)$ \\
\hline & Private employee & 7 & 43 & $2.69(1.04,6.92)$ & $0.29(0.02,14.47)$ \\
\hline & Farmer & 5 & 24 & $1.42(0.30,6.92)$ & $2.18(0.11,42.2)$ \\
\hline & Government employee & 6 & 13 & $0.78(0.26,2.38)$ & $0.64(0.03,14.47)$ \\
\hline \multirow[t]{2}{*}{ Living arrangements } & With husband & 38 & 323 & 1 & 1 \\
\hline & Alone & 8 & 27 & $2.52(1.07,5.94)$ & $0.29(0.016,5.34)$ \\
\hline \multirow[t]{2}{*}{ Status of pregnancy } & Wanted/planned & 36 & 303 & 1 & 1 \\
\hline & Unwanted/unplanned & 10 & 47 & $0.56(0.26,1.200)$ & $1.12(0.10,12.15)$ \\
\hline \multirow[t]{3}{*}{ Gravida (in number) } & 1 & 9 & 130 & $3.05(0.38,24.73)$ & $1.08(0.29,4.02)$ \\
\hline & $2-5$ & 36 & 176 & $9.00(1.20,67.46)$ & $9.82(1.08,89.5)$ \\
\hline & $\geq 6$ & 1 & 44 & 1 & 1 \\
\hline \multirow[t]{3}{*}{ Gestational age (in weeks) } & $\leq 12$ & 23 & 63 & $6.44(2.73,15.12)$ & $3.53(1.03,12.08)$ \\
\hline & $13-24$ & 15 & 146 & $1.81(0.75,4.40)$ & $1.04(0.34,3.18)$ \\
\hline & $\geq 25$ & 8 & 141 & 1 & 1 \\
\hline \multirow[t]{2}{*}{ History neonatal death } & Yes & 2 & 30 & $0.38(0.09,1.65)$ & $0.60(0.11,3.18)$ \\
\hline & No & 34 & 192 & 1 & 1 \\
\hline
\end{tabular}

Italic values indicate significance of $P$-value $(P<0.05)$ 
could be at the early age of pregnant women might fear the possibility of miscarriage/loss of pregnancy and the viability of the fetus.

\section{Conclusion}

In this study, the prevalence of perceived stress among pregnant women was relatively low. Having 2-5 pregnancies previously and gestational age less than 12 weeks were associated with perceived stress during pregnancy. Health care providers should give due attention to the screening of stress in the first trimester in order to reduce the likelihood of pregnancy-specific perceived stress.

\section{Limitations of the study}

This study was conducted in health facilities; hence the findings might not adequately reflect the stresses of the entire pregnant women in the community.

\section{Abbreviations}

ANC: antenatal care; AOR: adjusted odds ratio; Cl: confidence interval; PSS: perceived stress scale; SPSS: Statistical Package for Social Science; USA: United States of America.

\section{Acknowledgements}

We would like to thank Madda Walabu University for giving us an opportunity to work on identified thematic areas and financial grants. We are also grateful to our study participants, data collectors, head/directors of health facilities for their great contribution and support.

\section{Authors' contributions}

$A G, N A$, and FK conceived and designed the study, developed the methodology, supervised the data collection, analyzed and interpreted the data. All authors critically drafted and edited the manuscript. All authors read and approved the final manuscript.

\section{Funding}

Not applicable.

\section{Availability of data and materials}

The datasets generated and/or analyzed during the current study are not publicly available due to some privacy reasons, but part of the row datasets will be available in the recommended publicly available data repository of BMC or from the corresponding author on reasonable request.

\section{Ethics approval and consent to participate}

Ethical approval was obtained from a research review committee of Madda Walabu University. Letters were secured from Bale zone Health Bureau and respective hospitals. Written informed consent was obtained from each study participant. All information was kept confidential throughout the process of study, and the name of the participant was replaced by code. Withdrawal from the study at any point if they wished was assured.

\section{Consent for publication}

Not applicable.

\section{Competing interests}

The authors declare that they have no competing interests.

\section{Author details}

${ }^{1}$ Department of Nursing, College of Health Sciences, Debre Berhan University, Po. Box 445, Debre Berhan, Ethiopia. ${ }^{2}$ Department of Midwifery, College of Health Sciences, Debre Berhan University, Po. Box 445, Debre Berhan, Ethiopia.
Received: 10 May 2019 Accepted: 11 June 2019

Published online: 24 June 2019

\section{References}

1. Pais M, Pai MV. Stress among pregnant women: a systematic review. J Clin Diagn Res. 2018;12(5):LE01-4.

2. Talley L. Stress management in pregnancy. Int J Childbirth Educ. 2013;28(1). http://search.ebscohost.com/login.aspx?direct=true\&profi le $=$ ehost\&scope $=$ site\&authtype $=$ crawler\&jrn $=08878625 \& A N=84787$ 084\&h=KJiJh1elWgt9p7sGophuhn4RIPWZkomWW1\%2FL7X YC\%2FI4XNfxNVzUVS1DKsOimd\%2BiN8ytclOiMC9xhBz\%2Fnq8 Ar6g\%3D\%3D\&crl=c.

3. Shishehgar S, Dolatian M, Majd HA, Bakhtiary M. Perceived pregnancy stress and quality of life amongst Iranian women. Glob J Health Sci. 2014;6(4):270.

4. Ruiz R, Fullerton J. The measurement of stress in pregnancy. Nurs Health Sci. 1999;1(1):19-25.

5. Woods SM, Melville JL, Guo Y, Fan M-Y, Gavin A. Psychosocial stress during pregnancy. Am J Obstet Gynecol. 2010;202(1):61.e1-7.

6. Lynn FA, Alderdice FA, Crealey GE, McElnay JC. Associations between maternal characteristics and pregnancy-related stress among lowrisk mothers: an observational cross-sectional study. Int J Nurs Stud. 2011;48(5):620-7.

7. Ahmed AE, Albalawi AN, Alshehri AA, Al Blaihed RM, Alsalamah MA. Stress and its predictors in pregnant women: a study in Saudi Arabia. Psychol Res Behav Manag. 2017;10:97.

8. Iranzad I, Bani S, Hasanpour S, Mohammadalizadeh S, Mirghafourvand M Perceived social support and stress among pregnant women at health centers of Iran-Tabriz. J Caring Sci. 2014;3(4):287.

9. Pais M, Pai MV, Kamath A, George A, Noronha JA, Nayak BS, et al. Stress among antenatal women in India. Int J Nurs Care. 2014;2(2):63.

10. Vijayaselvi R, Beck MM, Abraham A, Kurian S, Regi A, Rebekah G. Risk factors for stress during antenatal period among pregnant women in tertiary care hospital of Southern India. J Clin Diagn Res. 2015;9(10):QC01.

11. Pantha S, Hayes B, Yadav B, Sharma P, Shrestha A, Gartoulla P. Prevalence of stress among pregnant women attending antenatal care in a tertiary maternity hospital in Kathmandu. J Womens Health Care. 2014;3(5):183.

12. Boakye-Yiadom A, Shittu S, Dutt J, Dapare P, Alhassan A. Perceived stress and anxiety among Ghanaian pregnant women. J Med Biomed Sci. 2015;4(2):29-37.

13. McCormick MC, Brooks-Gunn J, Shorter T, Holmes JH, Wallace CY, Heagarty MC. Factors associated with smoking in low-income pregnant women: relationship to birth weight, stressful life events, social support, health behaviors and mental distress. J Clin Epidemiol. 1990;43(5):441-8.

14. Lu MC, Chen B. Racial and ethnic disparities in preterm birth: the role of stressful life events. Am J Obstet Gynecol. 2004;191(3):691-9.

15. Marquis S, Butler E. Practice guidelines for prenatal and postnatal outreach in British Columbia, Canada. Victoria: Ministry for Children and Families; 2001.

16. Lau Y, Yin L. Maternal, obstetric variables, perceived stress and healthrelated quality of life among pregnant women in Macao, China. Midwifery. 2011;27(5):668-73.

17. Bat Conservation International. Bat Conservation International (Web Page). 2008. http://www.batcon.org.

18. Da Costa D, Larouche J, Dritsa M, Brender W. Variations in stress levels over the course of pregnancy: factors associated with elevated hassles, state anxiety and pregnancy-specific stress. J Psychosom Res. 1999;47(6):609-21.

19. Brown M-A. Marital discord during pregnancy: a family systems approach Fam Syst Med. 1994;12(3):221.

20. Pickler RH, McGrath JM, Reyna MBA, McCain N, Lewis MM, Cone MS, et al. A model of neurodevelopmental risk and protection for preterm infants. J Perinat Neonatal Nurs. 2010;24(4):356.

21. Wadhwa PD, Entringer S, Buss C, Lu MC. The contribution of maternal stress to preterm birth: issues and considerations. Clin Perinatol. 2011;38(3):351-84.

22. Collins Jr JW, editor. Very low birth weight in African-American infants: the effect of maternal lifetime exposure to interpersonal racial discrimination. In: The 130th Annual Meeting of APHA. 2002. 
23. Campbell SB, Cohn JF. The timing and chronicity of postpartum depression: implications for infant development. Postpartum Depress Child Dev. 1999:165. https://psycnet.apa.org/record/1997-08350-007.

24. Jacobsen T. Effects of postpartum disorders on parenting and on offspring. Postpartum Mood Disord. 1999:119-39. https://www.googl e.com/search?client=ms-opera-mini-android\&channel=new\&q=effec ts +of+postpartum+Disorder+on+parenting +and+on+offsp ring + by + jacobsen\&spell $=1 \&$ sa $=$ X\&ved $=2$ ahUKEwiyj4vXkPjiAhVXilwK HWO-DCKOBXOECAEQAO

25. Huizink AC, Robles de Medina PG, Mulder EJ, Visser GH, Buitelaar JK. Stress during pregnancy is associated with developmental outcome in infancy. J Child Psychol Psychiatry. 2003;44(6):810-8.

26. Cohen S, Kamarck T, Mermelstein R. Perceived stress scale. Measuring stress: a guide for health and social scientists. 1994. pp. 235-83. https:// www.mindgarden.com/132-perceived-stress-scale.

27. Mekonnen AG, Amogne FK, Kassahun CW. Risk factors of hyperemesis gravidarum among pregnant women in Bale zone Hospitals, Southeast Ethiopia: unmatched case-control study. Clin Mother Child Health. 2018;15(300):2.

28. Manzar MD, Salahuddin M, Peter S, Alghadir A, Anwer S, Bahammam AS Pandi-Perumal SR. Psychometric properties of the perceived stress scale in Ethiopia university students. BMC Public Health. 2019:19(1):41. https:// www.ncbi.nlm.nih.gov/m/pubmed/30626438/.
29. Madebo WE, YosefTT, Tesfaye MS. Assessment of perceived stress level and associated factors among health science students at Debre Birehane University, North Shoa Zone of Amhara Region, Ethiopia. Health Care Curr Rev. 2016:4:166.

30. Marcus SM, Flynn HA, Blow FC, Barry KL. Depressive symptoms among pregnant women screened in obstetrics settings. J Womens Health. 2003;12(4):373-80.

31. Shishehgar S, Dolatian M, Majd HA, Bakhtiary M. Socioeconomic status and stress rate during pregnancy in Iran. Glob J Health Sci. 2014;6(4):254.

32. Martin SL, Griffin JM, Kupper LL, Petersen R, Beck-Warden M, Buescher PA. Stressful life events and physical abuse among pregnant women in North Carolina. Matern Child Health J. 2001;5(3):145-52.

33. Rouhe H, Salmela-Aro K, Halmesmäki E, Saisto T. Fear of childbirth according to parity, gestational age, and obstetric history. BJOG. 2009;116(1):67-73.

\section{Publisher's Note}

Springer Nature remains neutral with regard to jurisdictional claims in published maps and institutional affiliations.
Ready to submit your research? Choose BMC and benefit from:

- fast, convenient online submission

- thorough peer review by experienced researchers in your field

- rapid publication on acceptance

- support for research data, including large and complex data types

- gold Open Access which fosters wider collaboration and increased citations

- maximum visibility for your research: over 100M website views per year

At BMC, research is always in progress.

Learn more biomedcentral.com/submissions 